\title{
AN INVERSE PROBLEM USING GREEN'S FUNCTIONS AND TFBGF METHOD TO INDENTIFICATE A MOVING HEAT SOURCE IN 3D HEAT CONDUCTION
}

\author{
S.S. Ri beiro, \\ G. C. Oli veira, \\ and G. Guimarães \\ Universidade Federal de Uberlândia \\ Depart amento de Engenharia Mecânica \\ Avenida João Naves de Ávila 2121, Santa \\ Mônica, Uberlândia, Minas Gerais, Brasil \\ sidney.ribeiros@hotmail.com \\ gabriela_costadeoliveira@hotmail.com \\ gguima@ufu.br \\ Received: May 31, 2018 \\ Revised: July 30, 2018 \\ Accepted: October 31, 2018

\section{NOMENCLATURE} \\ $\mathrm{T}$ temperature ${ }^{\circ} \mathrm{C}$ \\ $\mathrm{T}_{0} \quad$ initial temperature ${ }^{\circ} \mathrm{C}$ \\ $\mathrm{T}_{\infty} \quad$ ambient temperature ${ }^{\circ} \mathrm{C}$ \\ $\mathrm{x}, \mathrm{y}$ and $\mathrm{z}$ cordination system $\mathrm{m}$ \\ $\mathrm{q}_{\mathrm{g}}$ heat source generation $\mathrm{W} / \mathrm{m}^{3}$ \\ $\mathrm{k}$ thermal conductivity $\mathrm{W} / \mathrm{mk}$ \\ $\mathrm{u} \quad$ solid velocity $\mathrm{m} / \mathrm{s}$ \\ $\mathrm{L}_{1}, \mathrm{~L}_{2}$ and $\mathrm{L}_{3}$ solid dimensions $\mathrm{m}$ \\ $\mathrm{P}_{1}, \mathrm{P}_{2}$ and $\mathrm{P}_{3} \quad$ fixed position at solid $\mathrm{m}$ \\ W auxiliary variab $l{ }^{\circ} \mathrm{C}$ \\ $\mathrm{W}_{\infty}$ auxiliary a mbient temperature variable ${ }^{\circ} \mathrm{C}$ \\ h heat convection coeficient $\mathrm{W} / \mathrm{m}^{2} \mathrm{~K}$ \\ $\mathrm{G}^{*} \quad$ Green's function \\ $\mathrm{h}(\mathrm{t}) \quad$ impulse response \\ $\mathrm{H}$ transfer function \\ L Laplace transform \\ $\mathrm{L}^{-1} \quad$ inverse Laplace Transform
}

\begin{abstract}
Moving heat source are present in numerous practical problems in engineering. For example, machining process as the Gas tungsten arc welding (GTAW), laser welding, friction stirwleing process or milding problem. Moving heat source are also present in biological heating as the metabolism or in heat thermal treatment. All these cases, the heat input identification is a complex task and represents an important factor in the process optimization. The aim of this work is to investigate both the temperature field as the heat flux delivered to a piece during a process with moving heat source.
\end{abstract}

Keywords: inverse problem; analytical solution; moving heat source; green's function $\mathrm{t}$ time $\mathrm{s}$

\section{Greek symbols}

$\alpha \quad$ thermal difusivity $\mathrm{m}^{2} / \mathrm{s}$

$\beta_{\mathrm{m}}, \beta_{\mathrm{n}}$ and $\beta_{\mathrm{p}}$ eigenvalues

$\xi \quad$ auxiliary coordinate system $\mathrm{m}$

$\tau \quad$ time delay s

$\delta \quad$ Delta function

$\varepsilon \quad$ aleatory noise ${ }^{\circ} \mathrm{C}$

\section{INTRODUCTION}

Moving heat source are present in numerous pratical problems in ingeenring. For example, machining process as cutting, milling or welding process. Moving heat source are also present in biological heating as the metabolism or in heat thermal treatment. All this cases, the heat input identification is a complex task and represents an important factor in the optimization of the process.

Many investigators have studied welding heat flow problems, analytically, numerically, and experimentally. In the majority of these works, however, the values of the heat flux input is assumed to be known, taken from literature or determined by using calorimetric techniques. In fact, the heat flux that goes to the workpiece is unknown and it is determination represents an inverse problem. In this sense, the use of techniques found an inverse heat conduction problems can represent an alternative way to obtain the heat flux that goes to the workpiece.

Moving heat source estimation without use of minimization least square or optimization technique is the great advantages of the technique proposed here. The moving heat source can be obtained directly from the temperature measured since the $3 \mathrm{D}$ transient analytical solution is obtained and the TFBGF, (Fernandes, 2013) can be applied in that solution.

The temperature measurements are obtained using thermocouples at accessible regions of the workpiece surface while the theoretical temperatures are calculated from a 3D transient heat conduction thermal model with a moving heat source. The solution of thermal model is obtained analytically (direct problem) (Ribeiro, 2015). The inverse 
problem, it means, the moving heat source estimation uses the Transfer Function Based on Green's Function (TFBGF) method (Fernandes et al., 2015). This method is based on Green's function and in the equivalence between thermal and dynamic systems. This technique is a simple approach without iterative processes, and therefore extremely fast. From the knowledge of both the temperature profile (hypothetical or experimental temperature far from the heat source) and of the transfer function it is possible to estimate the heat flux by an inverse procedure of the Fast Fourier Transform (IFFT). The TFBGF method was adapted to solve an inverse heat conduction problem with a moving heat source. Simulated and experimental test were used for estimating the heat source delivered to the workpiece.

\section{GOVERNING EQUATION}

The thermal problem can be described by the $3 \mathrm{D}$ heat conduction equation in the fixed $\mathrm{x}, \mathrm{y}, \mathrm{z}$ coordinate system, assuming constant thermal properties, as

$$
\begin{aligned}
& \frac{\partial^{2} T}{\partial x^{2}}+\frac{\partial^{2} T}{\partial y^{2}}+\frac{\partial^{2} T}{\partial z^{2}}+\frac{q_{g}}{k} \delta(x-u t) \delta(y-P y) \delta(z-P z)= \\
& \frac{1}{\alpha} \frac{\partial T}{\partial t}-u \frac{\partial T}{\partial x}
\end{aligned}
$$

Subjected to the first kind boundary conditions:

$$
\begin{aligned}
& T(0, y, z, t)=T\left(L_{1}, y, z, t\right)=T_{0} \\
& T(x, y, z, t)=T\left(x, L_{2}, z, t\right)=T_{0}
\end{aligned}
$$

and the initial condition

$$
T(x, y, z, 0)=T_{0}
$$

Machining, grinding, cutting, and surfaces sliding, that has energy generated as a result of friction heating in a area with depth penetrarion, it means a volume heat source. In this sense, in this work, the heat source moving will be considered a point heat source of constant strength delta(W), releasing its energy continuously over time while moving along the $\mathrm{x}$ axis in the positive $\mathrm{x}$ direction with a constant velocity $u$, in a stationary medium that is initially at zero temperature. After performing variables change using:

$$
T(x, y, z, t)=W(x, y, z, t) \exp \left(\frac{u x}{2 \alpha}-\frac{u^{2} t}{4 \alpha}\right)
$$

In addition, in the solution of moving heat source problems, it is convenient to let the coordinate system move with the source Ozisik (1993). This is achieved by

$$
\xi=x-u t
$$

Thus, considering Eqs. (4) and (5) the governing equation is obtained as

$$
\begin{aligned}
\frac{\partial^{2} W}{\partial \xi^{2}} & +\frac{\partial^{2} W}{\partial y^{2}}+\frac{\partial^{2} W}{\partial z^{2}} \\
& +\frac{q_{g}}{k} \delta\left(\xi-P_{\xi}\right) \delta(y-P y) \delta(z-P z)=\frac{1}{\alpha} \frac{\partial W}{\partial t}
\end{aligned}
$$

subjected to the boundary conditions

$$
\begin{aligned}
& W(0, y, z, t)=W\left(L_{1}, y, z, t\right)=0 \\
& W(\xi, 0, z, t)=W\left(x, L_{2}, z, t\right)=0 \\
& W(\xi, y, 0, t)=W\left(\xi, y, L_{3}, t\right)=0
\end{aligned}
$$

and

$$
\begin{array}{r}
\left.k \frac{\partial W}{\partial z}\right|_{z=L_{3}}+W\left(L_{3}, t\right)\left(h+\frac{k u}{2 \alpha}\right) \\
=h W_{\infty} e^{\frac{-u L_{3}}{2 \alpha}-\frac{u^{2} t}{4 \alpha}}
\end{array}
$$

where

$$
h+\frac{k u}{2 \alpha}=h_{e f f}
$$

The term $h_{\text {eff }}$ in Eq. (11) is the effective heat convection coefficient Beck et al. (2010). Equation (6) can then be solved using Green's function method Beck and McMasters (2004) as

$$
\begin{array}{r}
W=\int_{\tau=0}^{t} \int_{\xi^{\prime}=0}^{L_{1}} \int_{y^{\prime}=0}^{L_{2}} \int_{z^{\prime}=0}^{L_{3}} G^{*}(t-\tau) \\
q_{g}(\tau) d z^{\prime} d y^{\prime} d \xi^{\prime} d \tau
\end{array}
$$

where

$$
\begin{aligned}
& G^{*}\left(\xi, y, z, t \mid \xi^{\prime}, y^{\prime}, z^{\prime}, t-\tau\right)= \\
& G(t-\tau) \delta\left(\xi^{\prime}-P_{\xi}\right) \\
& \quad \times \delta\left(y^{\prime}-P_{y}\right) \delta\left(z^{\prime}-P_{z}\right) e^{\frac{u P \xi}{2 \alpha}-\frac{u^{2} \tau}{4 \alpha}}
\end{aligned}
$$

and the Green's function for th is problem can be obtained by Beck et al. (2010) 


$$
\begin{aligned}
& G\left(x, y, z, t \mid x^{\prime}, y^{\prime}, z^{\prime}, t-\tau\right)= \\
& \frac{8}{L_{1} L_{2} L_{3}} \sum_{m=1}^{\infty} \sum_{n=1}^{\infty} \sum_{p=1}^{\infty} e^{-\beta_{m}^{2} u} e^{-\beta_{n}^{2} u} e^{-\beta_{p}^{2} u} \\
& \times \operatorname{sen}\left(\beta_{m} x\right) \operatorname{sen}\left(\beta_{m} x^{\prime}\right) \operatorname{sen}\left(\beta_{n} y\right) \\
& \times \operatorname{sen}\left(\beta_{n} y^{\prime}\right) \operatorname{sen}\left(\beta_{p} z\right) \operatorname{sen}\left(\beta_{p} z^{\prime}\right) \\
& \frac{\beta_{p}^{2}+B^{2}}{\beta_{p}^{2}+B^{2}+B}
\end{aligned}
$$

where

$$
\beta_{m}=\frac{m \pi}{L_{1}}, \beta_{n}=\frac{n \pi}{L_{2}},-B=\beta_{p} \cot \left(\beta_{p}\right), B=\frac{h L_{3}}{k}, u=\alpha(t-\tau) .
$$

original temperature can be recovered by Eq.(4).

$$
T(x, y, z, t)=W(x, y, z, t) \exp \left(\frac{u x}{2 \alpha}-\frac{u^{2} t}{4 \alpha}\right)
$$

Figure (2) presents the temperature generated by 3D analytical solution using a Gaussian heat source presented in figure (1) at the point $\left(0.00,0.05, L_{3}\right)$, using $\alpha=23.1 \times 10^{-6} \mathrm{~m}^{2} \mathrm{~s}^{-1}, \quad k=80.2 \mathrm{Wm}^{-1} \mathrm{~K}^{-1}$ and heat source speed $u=0.001 \mathrm{~ms}^{-1}$ at initial position $\left(0.00,0.05, L_{3}\right)$ for the parallepiped with edges $L_{1}=L_{2}=L_{3}=0.1 \mathrm{~m}$.

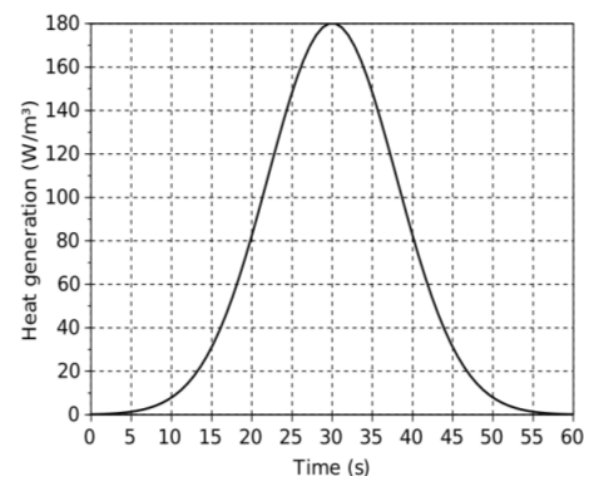

Figure 1. Gaussian heat source generation.

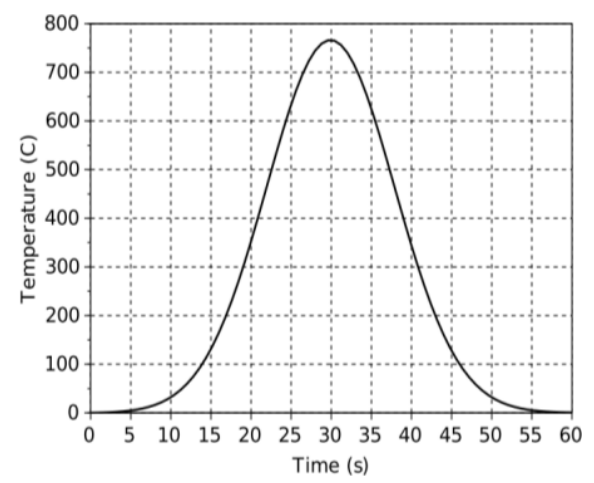

Figure 2. Temperatures for a gaussian heat generation.

\section{The TFB GF Method}

For any dynamic system (Fig.3), the relation between input $\mathrm{X}(\mathrm{t})$ and output $\mathrm{Y}(\mathrm{t})$ can be given by the convolution equation.

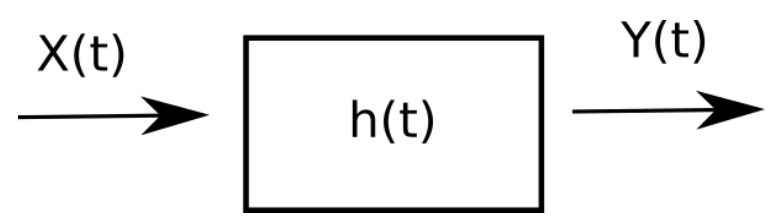

Figure 3. Diagram for dyna mical systems.

$$
Y(t)=h(t) * X(t)=\int_{-\infty}^{+\infty} h(t-\tau) X(\tau) d \tau
$$

That in Laplace domain is expressed by the multip lication

$$
Y(x, s)=H(x, s) X(s)
$$

In this sense, input $\mathrm{X}$ in Laplace domain can be calculated by

$$
X(s)=(1 / H(x, s)) Y(x, s)
$$

Or in the time domain by the deconvolution

$$
X(t)=L^{-1}\{1 / h(x, t)\}^{*} Y(x, t) .
$$

Considering the heat source for input system and temperature field output, we can obtain the impulse response for this problem.

\section{Analytical Impulse Response Identification}

The proposed methodology for identification of the analytical impulse response is based on the theory of dynamical systems of one input and one output. It can be observed that for any input $\mathrm{X}(\mathrm{t})$ and the output $\mathrm{Y}(\mathrm{t})$, the transfer function, $\mathrm{H}(\mathrm{t})$, remains the same. Therefore, by comparing Eq.(13) and Eq.(16), and using transformation Eq. (4). In this case we use $q_{g}(\tau)=\delta(\tau)$. After the integral performing the Transfer function can then be calculated as

$$
\begin{aligned}
& h(\xi, y, z, t)= \\
& \frac{\alpha}{k} \frac{8}{L_{1} L_{2} L_{3}} \sum_{m=1}^{\infty} \sum_{n=1}^{\infty} \sum_{p=1}^{\infty} e^{-\left(\beta_{m}^{2}+\beta_{n}^{2}+\beta_{p}^{2}\right) \alpha t} \\
& \operatorname{sen}\left(\beta_{m} \xi\right) \operatorname{sen}\left(\beta_{m} P_{\xi}\right) \operatorname{sen}\left(\beta_{n} y\right) \operatorname{sen}\left(\beta_{n} P_{y}\right) \\
& \operatorname{sen}\left(\beta_{p} z\right) \operatorname{sen}\left(\beta_{p} P_{z}\right) e^{\frac{u P_{\xi}}{2 \alpha}}\left(\frac{\beta_{p}^{2}+B^{2}}{\beta_{p}^{2}+B^{2}+B}\right)
\end{aligned}
$$


Thus, the heat source is obtained using

$$
T(s)=q_{g}(s) H(s) \Rightarrow q_{g}(s)=\frac{T(s)}{H(s)}
$$

The heat source moving then can be obtained in the original variable as

$$
\begin{gathered}
W(x, y, z, t)=T(x, y, z, t) \mathrm{e}^{\frac{-u_{x} x}{2 \alpha}+\frac{u_{x}^{2} t}{4 \alpha}} \\
q_{g}(s)=\exp \left(\frac{-u_{x} x}{2 \alpha}\right) \frac{T(x, y, z,(s+b))}{H(s)}
\end{gathered}
$$

where

$$
\alpha=\frac{-u x}{2 \alpha}
$$

and

$$
b=\frac{-u^{2} t}{4 \alpha}
$$

Thus, the solution of the inverse problem (in original variable $\mathrm{T}$ ) is obtained by means of one of Eq. (22) in the Laplace do main or, in the time do main by Eq. (19) Fernandes et al. (2015). In this case, the input is the heat source $q_{g}(s)$, that can be estimated from the impulse response $\mathrm{H}(\mathrm{s})$ and from the temperature measured at any position of the system. Using the following expression as mentioned, heat source estimation can be done in the Laplace domain or in time domain using the software Scilab with functions fast Fourier transform and inverse Fourier transform (fft) as the following expression.

$$
q_{g}(s)=(1 / H(x, s)) W(x, s)
$$

Or using the deconvolution function.

$$
q_{g}(t)=\{1 / h(x, t)\}^{*} W(x, t)
$$

\section{Heat Source Identification}

The three-dimensionalis analyzed in this section. Temperature distributions for the direct problem are generated using the solution of Eq. (15) considering a moving gaussian heat source $q_{g}(t)$ a shown in (Fig.1). Random errors are then added to these temperatures. The temperatures with error are then used in the inverse algorithm to reconstruct the imposed heat source. The simulated temperatures are calculated from the following equation. Using analytical solution, impulse response and hypothetical temperatures we can obtain the moving heat source term.

$$
Y(t)=T(x, y, z, t)+\varepsilon
$$

With the hypothetical temperatures (without added noise) calculated using Eq. (15) and the impulse response of the system (Fig. 4) calculated using Eq. (22) we obtain the temperature that will be used for estimations of the heat moving source using Eqs. (26 or 27). Eqs. (15) or (16) can also be used to estimate the heat moving source using temperatures at each position $\mathrm{x}, \mathrm{y}, \mathrm{z}$ The respective temperature evolution for each position heat source is presented in Fig. (1 ). Figure (4) presents the impulse response relative to the thermocuple position that will be used to estimate the moving heat source. Any par Temperature/heat transfer fucntion can be used to the estiamtion. The impulse response presents the same behavior for the any case because only dependent of material used.

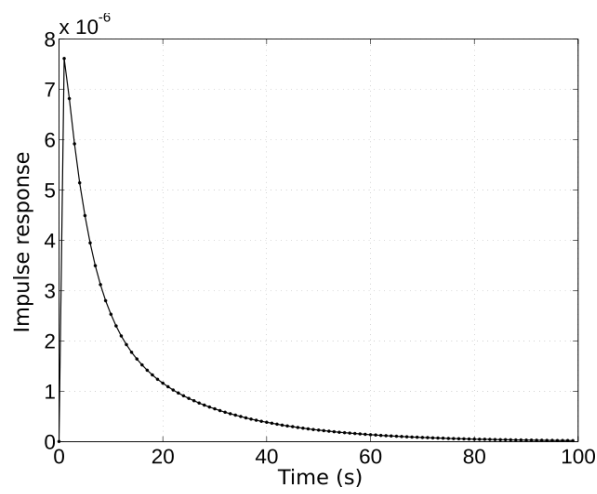

Figure 4, Impulse response.

Figure (5) and presents the heat source estimated using $\left(0.02,0.04, L_{3}\right)$ position.

Since the heat moving heat source has been obtained, temperature can be calculated for the any region. In order to compare the results, Fig. (6) presents a comparison between simulated temperature and calculated temperatures using heat source estimated.

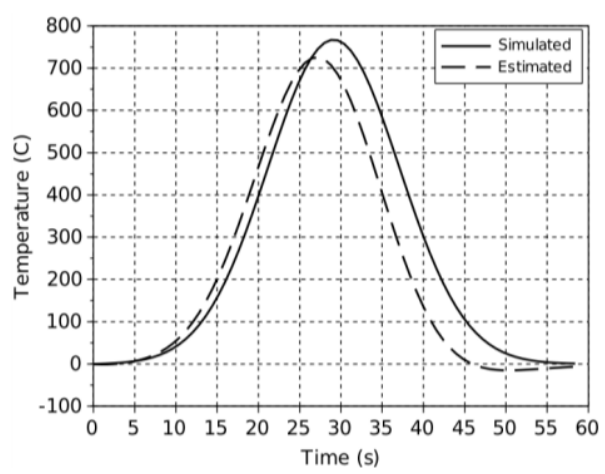

Figure 5. Comparison between estimated and theoretical heat source. 


\section{CONCLUS IONS}

The moving heat source has been obtained directly from the temperature measured since the $3 \mathrm{D}$ transient analytical solution is obtained and the TFBGF can be applied in that solution. Use of he ransfer unction Based on Green's Function (TFBGF) method allows the estimation of heat source without iterative processes, and therefore extremely fast. From the knowledge of both the temperature profile (hypothetical or experimental temperature far from the heat source) and of the transfer function it is possible to estimate the heat flux by an inverse procedure of the Fast Fourier Transform (IFFT).

\section{ACKNOWLEDGEMENTS}

The authors thanks to brasilian agencies CAPES, CNPq and FAPEMIG for their collaboration in this work.

\section{REFERENCES}

Beck, J. V., Cole, K. D., Haji-Sheikh, A., and Litkouhi, B., 2010, Heat Conduction Using Green's Functions, Series in Computacional and Physical Processes in Mechanics and Thermal Sciences, Taylor \& Francis Group.

Beck, J., and McMasters, R., 2004, Solutions for Multi-Dimensional Transient Heat Conduction with Solid Body Motion, International Journal of Heat and Mass Transfer, Vol. 47, pp. 3757-3768.

Fernandes, A. P., 2013, Função Transferência Analítica Aplicada a Solução de Problema Inverso em Condução de Calor, Doctoral Thesis, Universidade Federal de Uberlândia, Uberlândia, MG. (in Portuguese)

Fernandes, A. P., Santos, M. B., and Guimaraes, G., 2015, An Analytical Transfer Function Method to Solve Inverse Heat Conduction Problems, Applied Mathematical Modelling, Vol. 39, No. 22, pp. 68976914.

Özisik, M. N., 1993, Heat Conduction, WileyInterscience publication, Wiley.

Ribeiro, S. S., 2015, Condução de Calor Envolvendo Fontes Móveis, Master Thesis, Universidade Federal de Uberlândia, Uberlândia, MG. (in Portuguese) 